\title{
a língua da escola: alienadora ou emancipadora? ${ }^{1}$
}

\author{
jan masschelein ${ }^{2}$ \\ universidade católica de lovaina - bélgica \\ maarten simons ${ }^{3}$ \\ universidade católica de lovaina - bélgica
}

resumo

A escola frequentemente é acusada como uma maquinaria normalizadora, colonizadora e alienante que está mais ou menos impondo e reproduzindo violentamente uma certa ordem social, principalmente mediante a língua usada e (a ser) aprendida. Algumas dessas análises são famosas. Uma delas, a sociolinguística de Basil Bernstein, faz uma distinção entre o uso de um código restrito e um elaborado, e sugere uma clara relação disso com a classe social. Outra delas é o ataque afiado de Illich à maneira pela qual várias autoridades políticas impõem uma língua 'nacional', desvalorizando desse modo línguas vernáculas. E outra, obviamente, é a crítica de Paulo Freire à maneira pela qual as 'palavras' (língua) do grupo social dominante (os opressores) não somente alienam os oprimidos de suas experiências, mas também operam como um mecanismo que instala e reproduz a injusta ordem social existente. Ainda que reconheçamos a importância e o valor dessas análises, em nossa contribuição argumentaremos, desde uma perspectiva estritamente pedagógica, que a escola sempre implica uma ruptura e um impacto (violentos) nas línguas 'naturais' (incluindo, de qualquer forma, também a língua do grupo dominante). E tentaremos indicar que, se a escola de fato opera como uma escola (isto é, não como uma instituição, mas como um tipo muito específico de se reunir pessoas e coisas, o qual espacializa 'tempo livre' e gramaticaliza o mundo), então a língua da escola também é uma língua por vir (ou em-form-ação), que invoca também uma comunidade por vir. Por consequência, a língua escolar é sempre artificial e em formação, e precisamente por isso, é também realmente emancipadora.

palavras-chave: escola; pedagogia; experiência.

\section{the language of the school: alienating or emancipating?}

abstract

The school has often been accused of being a normalizing, colonizing and alienating machinery that is more of less violently imposing and reproducing a certain social order and this mainly through the language which is used and (to be) learned. Some of the analyses are famous. The sociolinguistic one of Basil Bernstein making a distinction between the use of a restricted and an elaborated code and suggesting a clear relation to social class. Illich' sharp attack of the way in which various political authorities imposed one 'national' language thereby devaluating vernacular languages. And of course, Paulo Freire's critique of the way in which the 'words' (language) of the dominant social group

\footnotetext{
${ }^{1}$ Este texto é uma versão atualizada e revisada do apresentado em inglês durante o VIII Colóquio Internacional de Filosofia e Educação, UERJ, outubro de 2016. A tradução é de Danilo J. S. Botelho, doutorando em filosofia da educação da Universidade Federal de Santa Catarina, USC. Email: ecoitaipu@gmail.com. Embora alguns títulos de livros citados no texto tenham sido traduzidos, o ano de publicação corresponde ao título da citação original presente nas referências.

2 E-mail: jan.masschelein@kuleuven.be

${ }^{3}$ E-mail: maarten.simons@kuleuven.be
} 
(the oppressors) not only alienate the oppressed from their experiences but also operates as a mechanism to install and reproduce the existing unjust social order. While recognizing the importance and value of these analyses, in our contribution we will argue from a strictly pedagogical perspective that school always implies a (violent) rupture and impingement on the 'natural' language (including however also the language of the dominant group). And we will try to indicate that if the school actually operates as a school (that is not as an institution, but as a very particular kind of gathering of people and things that spatializes 'free time' and grammatizes the world), then the language of the school is also always a language to come (or in-form-ation) which invokes also a community to come. And hence, school language is always artificial and in the making and precisely therefore also truly emancipating.

keywords: school; pedagogy; experience.

\section{la lengua de la escuela: ¿alienadora o emancipadora?}

resumen

La escuela frecuentemente es acusada como una maquinaria normalizadora, colonizadora y alienante que está más o menos imponiendo o reproduciendo violentamente una cierta orden social, principalmente mediante la lengua usada y (a ser) aprendida. Alguno de esos análisis son famosos. Uno de ellos, la socioliguistica de Basil Berntein, hace una distinción entre el uso de un código restricto y uno elaborado y sugiere una clara relación de eso con la clase social. Otra de ellas es el afilado ataque de Illich, la manera por la cual varias autoridades políticas impone una lengua "nacional" desvalorizando de este modo lenguas vernáculas. Y otra, obviamente, es la crítica de Paulo Freire a la manera por la cual las "palabras" (lengua) del grupo social dominante (los opresores) no solamente alienan los oprimidos de sus experiencias, sino también operan como un mecanismo que instala y reproduce la injusta orden social existente. Aunque reconozcamos la importancia y el valor de esos análisis, en nuestra contribución argumentamos, desde una perspectiva estrictamente pedagógica, que la escuela siempre implica una ruptura y un impacto (violento) en las lenguas "naturales" (incluyendo, de cualquier forma, también la lengua del grupo dominante). E intentaremos indicar que, si la escuela de hecho opera como una escuela (esto es, no como una institución, pero como un tipo específico de reunir personas y cosas, lo cual espacializa "tiempo libre" y gramatizaliza el mundo), entonces la lengua de la escuela es también una lengua por venir (o en-forma-ción), que invoca también una comunidad por venir. En consecuencia, la lengua escolar es siempre artificial y en formación, y precisamente por eso, es también realmente emancipadora.

palabras clave: escuela; pedagogía; experiencia. 
a língua da escola: alienadora ou emancipadora?

\section{em defesa de nossa defesa}

Pode ter soado ultrapassado ou arrogante, conservador e, para alguns, até agressivamente neocolonial tentar defender a escola como nós afirmamos no título do pequeno livro que foi publicado em Português como Em defesa da escola: uma questão pública em 2014. De fato, em muitos diferentes lugares por toda parte do mundo (incluindo o contexto brasileiro ou, de forma mais abrangente, o contexto sul-americano), a escola tem sido acusada de ser um maquinário normalizador, colonizador e alienador que está mais ou menos impondo, estabelecendo ou reproduzindo violentamente uma certa ordem social (muitas vezes a do estadonação) por meio da qual, certamente, a língua desempenha um papel central. De fato a língua da escola é uma questão que nós não abordamos em nossa defesa, porém pretendemos fazer uma tentativa muito preliminar, indefesa e, portanto, incontestavelmente muito discutível de lidar com isso nesta contribuição. No entanto, queremos reiterar explicitamente que não pretendemos defender a escola como uma instituição do estado. Quisemos e ainda queremos tirar a escola das mãos daqueles que confundem escola com todos os tipos de mecanismos manipuladores e institucionalizadores. Nós não ignoramos ou trivializamos esses mecanismos - de modo algum -, mas pensamos que é mais justo falar educacionalmente e apreciativamente da escola primeiro. Nossa ambição foi articular experiências de escola, não as experiências institucionalizadas que são frequentemente mobilizadas para atacar a escola (Simons; Masschelein, 2016). Mas para ser claro desde o início, queremos salientar que escola, justamente como democracia, é uma invenção (igualmente emergindo na Grécia antiga e talvez ainda mais radical que a invenção da própria democracia) e, enquanto tal, não tem nada a ver com o tipo de aprendizagem informal ou natural que é frequentemente (implícita ou explicitamente) estimado por aqueles que se opõem a institucionalizadas (ou 'artificiais') formas de aprendizagem. 
Na verdade, assumimos que nossa crítica explícita às acusações dirigidas à escola, bem como a atenção extensiva que demos a todos os tipos de domesticação da escola poderiam ter garantido ao leitor do livro que estamos muito atentos à maioria das críticas (incluindo aquelas de radicais desescolarizadores tais como Ivan Illich) que têm sido muitas vezes devidamente dirigidas à escola. Esperávamos que isso ajudaria o leitor, ao menos por um momento, a superar a forte (muito comum e, de fato, acrítica) inclinação a imediatamente recriar todas aquelas bem conhecidas e facilmente reconhecíveis frustrações com respeito à escola (que é chata, disciplinadora, formal, 'morta', não relacionada ao mundo real, excludente etc.). Convidamos o leitor a nos acompanhar em nosso esforço para explorar o que faz de uma escola uma escola de um ponto de vista educacional. Esse não é um ponto de vista sociológico em termos de funções, tampouco filosófico em termos de ideias ou razões, nem psicológico em termos de desenvolvimento, tampouco ético em termos de valores, normas ou relações interpessoais, e nem político em termos de conflito ou interesses. É educacional em termos das operações reais e efetivas performadas por um arranjo específico de pessoas, tempo, espaço e matéria. Essas operações são por si mesmas emancipatórias (se a escola não é domesticada).

\section{resumindo a escola}

Deixe-nos brevemente resumir estas operações porque teremos que mantêlas em mente quando lidarmos com a questão da língua escolar: 1. a operação de considerar cada um como 'estudante' ou 'pupilo', isto é, suspender, não destruir, os laços de família e estado ou qualquer comunidade definida ou 'fechada'; 2. a operação de suspensão, isto é, pôr temporariamente fora de efeito a habitual ordem e uso de coisas; 3. a operação de fazer 'tempo livre', isto é, materialização ou espacialização daquilo que os gregos chamavam 'skholé': o tempo para estudo e exercício; 4. a operação de tornar (conhecimento, práticas) público e (os) pôr sobre a mesa (o que também poderia ser chamado uma profanação); 5. a operação de fazer 'atento' ou formar atenção contando com um duplo 'amor', por ambos, pelo 
mundo e pela nova geração, e com práticas disciplinadoras ${ }^{4}$ para fazer atenção e renovação possíveis. A escola (como forma pedagógica) se refere, então, a uma associação de pessoas e coisas organizadas como uma maneira de lidar com, prestar atenção a, ocupar-se de algo - entrar e estar em sua companhia -, em que essa atenção implica estruturalmente uma exposição. A escola nesse sentido, isto é, como uma forma pedagógica, não é nem orientada em direção a, nem domada por uma utopia política, tampouco por um ideal normativo de uma pessoa, mas é per se a materialização de uma crença utópica: qualquer um pode aprender qualquer coisa. Essa crença é, em nossa visão, não um tipo de meta ou objetivo (projetado no futuro), mas sim o ponto de partida. Há claramente outros pontos de partida possíveis quando se vem a aprender (alguns estudantes poderiam a priori ser excluídos de certos assuntos, habilidade natural é um decisivo critério para decidir sobre quando e o que aprender). A escola, para nós, é o fazer possível do 'qualquer um pode' por um lado, e do 'qualquer coisa' por outro. Em outras palavras, em vez de pensar sobre como seria uma escola utópica ou um sistema educacional utópico (como é frequentemente o caso), sugerimos olhar para a escola mesma, por meio daquilo que ela faz através de sua forma pedagógica, como a materialização da utópica ideia de que qualquer um pode aprender qualquer coisa. O que a forma escolar faz (se ela opera como uma escola!) é um duplo movimento de levar alguém a uma posição de ser capaz (e então, transformar esse alguém em um pupilo ou estudante), o que é ao mesmo tempo uma exposição a algo de fora (e então, um ato de apresentar e expor o mundo).

Além do mais, como já mencionamos acima, estamos atentos a como, desde seus primórdios até hoje, a 'escola' como forma pedagógica tem sido objeto de todos os tipos de táticas e estratégias, mais ou menos efetivas, para neutralizar, recuperar, instrumentalizar ou domá-la, significando que aquilo a que se chama escola muitas vezes não é escolar de modo algum. E como hoje, parcialmente ligado aos desenvolvimentos em TIC (e-learning), é dito até mesmo que a escola

\footnotetext{
${ }^{4}$ Esta disciplina não é sobre normalizar corpos e práticas, mas sim sobre viabilizar atenção e ficar em forma para tratar de. Poder-se-ia pensar na disciplina do atleta para manter seu corpo (e mente) em boa forma.
} 
em breve vai desaparecer. E é claro, nossa defesa da escola não ignorou as críticas devastadoras e profundas à escola de que ela seria algo como uma prisão, como um maquinário subjugador, opressor, colonizador, bancário ou como uma tecnologia de poder ultrapassada. Todavia, nós não quisemos sustentar que a escola que conhecemos hoje, como uma instituição ou organização, seja escolar no sentido que nós tentamos elaborar. Mas acreditamos, até hoje ainda, que vale a pena tentar desenterrar as operações radicais e revolucionárias da escola como prática e organização pedagógica muito própria de tornar coisas públicas e de reunir pessoas e mundo, que emergiu na Grécia.

Nós de fato alegamos que, justamente como os gregos inventaram uma maneira específica de lidar com a vida em comum, que se chama democracia (a qual tem provocado desde então, é claro, fortes questões e debates relativos a sua 'essência', sua 'conveniência', sua 'efetividade' etc.), eles também inventaram uma maneira específica de lidar com o mundo comum em relação às novas gerações. Isso não é socialização ou iniciação, mas precisamente educação escolar, isto é, tirar a nova geração de (qualquer) família e conseguir levá-la à escola. Escola, primeira e primordialmente, como uma organização particular de tempo, espaço e matéria onde jovens são trazidos à companhia de (algo do) mundo de uma maneira específica. Temos tentado explorar o mais específico dessa invenção educativa, e não idealizar o passado (não se trata, de modo algum, de romantizar a escola), ou pior, retornar ao passado (restaurar a escola tradicional). A razão de termos feito essa abordagem é que pensamos que ainda é digno lidar com o futuro de nosso mundo e das próximas gerações desta maneira pedagógica que podemos chamar de escola. Embora, justamente como a democracia, ela permanece uma questão para ser discutida e para se interessar (isto é, uma questão pública). Muito sobre a história da escola e as acusações detonadas contra ela parecem ser a articulação de um desprezo disseminado contra praticamente qualquer um que esteja envolvido com educação.

Há muitas versões deste olhar depreciativo à educação, abrangendo desde a frequentemente-repetida afirmação de que ensinar não é um trabalho real, até a 
pesquisa educacional não ser verdadeira pesquisa, bem como a teoria e filosofia da educação serem marginais. Segundo nossa perspectiva, esse desprezo na verdade expressa como a sociedade lida com o que é imaturo, com menores, e que sempre se assume e se protege a ideia de que estar envolvido em questões sérias requer um tipo de maturidade ou de ser adulto. Não há aí sempre um medo profundo motivando esse tipo de olhar depreciativo? Ele resulta de reconhecer que a próxima geração se torna realmente uma nova geração, e está, direta ou indiretamente, questionando aquilo que os adultos valoram e tomam por garantido. Na obra Em defesa da escola, tomamos o risco de usar a noção de escola para a configuração sempre artificial de espaço-tempo que faz essa radical experiência educacional possível, em vez de usar a noção para o que torna essa experiência impossível. Na verdade, pensamos que é nosso dever como teóricos da educação tirar a noção de escola das mãos daqueles que a usam para expressar frustrações ou expectativas políticas, econômicas e éticas (isto é, para instrumentalizá-la em relação a ideais ou projetos políticos ou éticos). Se a escola não atende a expectativa de alguém, não é porque os jovens também (algumas vezes) não atendem expectativas, e então eles não se adaptam ou não querem se adaptar à imagem que temos em mente para eles. Se for esse o caso, tudo isso é sobre o medo da escola, na medida em que escola refere-se ao tempo e espaço que começa desde a assunção de que seres humanos não tem (natural, ou social, cultural etc.) destino, e desta forma deveriam ter a oportunidade de encontrar seu próprio destino. Queremos reservar a noção de escola para essa assunção simples mas de longo alcance. E desescolarizar, para nós, refere-se à assunção oposta de que a sociedade tem que impor um destino às pessoas jovens por meio do desenvolvimento de seus assim-chamados talentos naturais, da projeção de uma imagem pré-definida da pessoa educada, do cidadão verdadeiro, da aprendizagem permanente, etc.

\section{exercícios em familiarização}

Tem-se insinuado que, ao defendermos a escola, nós estejamos olhando para o passado de uma maneira idealizada, de costas para o futuro e sem notar childhood E philosophy, rio de janeiro, v. 13, n. 27, maio-ago. 2017, pp. 193-212 issn 1984-5987 199 
desenvolvimentos históricos cruciais, desafios correntes e outras conceitualizações convenientes. Não estamos seguros disso. Experienciamos a nós mesmos vivendo no presente e tentando abrir outro futuro por meio da intervenção nas conceitualizações correntes da escola, incluindo nas narrativas históricas (de normalização elevada, educacionalização etc.) que são parte de nossas conceitualizações. Nesse sentido, nosso livro é talvez uma contranarrativa. $\mathrm{Ou}$ para continuar em um idioma foucaultiano: o livro não concebe uma ontologia crítica do presente, mas sim criativa, e a história não é usada para "desfamiliarizar" por alertar como a educação escolar é em realidade opressiva devido a poderes políticos, econômicos ou outros; mas sim para "familiarizar" por recordar o que a escola torna possível e por lembrar que nós fomos jovens também.

Para esclarecer melhor o que estávamos e estamos tentando fazer, e o que estamos defendemos e achamos muito digno de defesa - e que em verdade não é nem 'ensino' nem 'aprendizagem', mas 'escola' -, queremos aproveitar essa oportunidade para abordar, de uma maneira "familiarizante", a questão realmente difícil e desafiadora da língua da escola. Uma questão que surgiu com força em debates que tivemos a respeito de nosso livro no Brasil durante os últimos dois anos, mas que é agora também muito debatida em nosso próprio país no que se refere às questões de migrações (incluindo a chegada de refugiados) e identidade (nacional). É uma questão enfaticamente e talvez também paradigmaticamente presente em Bruxelas, a qual não é somente a capital da Bélgica (com suas três línguas oficiais) e da 'Europa' ('reconhecendo' todas as línguas 'nacionais' de seus estados-membro), mas também de outro modo um ambiente urbano extremamente multicultural/multilíngue (mais de 110 línguas são faladas). A questão da língua da escola é, por certo, também uma que já recebeu bastante atenção de teóricos e críticos lidando com 'escola' em relação com questões sociais tais como (neo-)colonialismo, justiça, igualdade. Algumas das análises são famosas e influentes. Por exemplo, a sociolinguística de Basil Bernstein (1971) faz uma distinção entre o uso de um código restrito e um elaborado, e sugere uma clara 
relação com a classe social. Uma análise que também Pierre Bourdieu e JeanClaude Passeron (1970) sustentaram, ainda que dentro de outro sistema teórico. O ataque afiado de Ivan Ilich à maneira pela qual várias autoridades políticas impõem uma língua 'nacional', desvalorizando desse modo línguas vernáculas (1981/2009). E obviamente a crítica de Paulo Freire à maneira pela qual as 'palavras' (língua) do grupo social dominante (os opressores) não só alienam os oprimidos de suas experiências, mas também operam como um mecanismo para instalar e reproduzir a ordem social injusta existente (1968/1970).

Ainda que reconheçamos a importância e valor dessas análises, e voltaremos a algumas delas, em nossa contribuição tentaremos oferecer algumas reflexões desde uma perspectiva diferente. Deveríamos dizer também desde o começo que nós não temos uma curta resposta clara e definida; dessa forma, não faremos um argumento sistemático, mas queremos oferecer algumas reflexões em forma de sugestões, hipóteses e possíveis consequências. Essas reflexões não pretendem resolver a questão da língua na escola, mas sim abrir (apenas começar!) outra abordagem a esse problema, a qual chamamos de estritamente pedagógica, alinhando com o que indicamos antes: pensar sobre a língua começa por (os requisitos da) escola (e não pelo indivíduo, a família, sociedade) como uma organização para oferecer aos 'menores' (e talvez também às minorias) simultaneamente a oportunidade de encontrar ou definir sua própria destinação (isto é, tornar-se pupilos ou estudantes) e de questionar direta ou indiretamente aquilo que 'adultos' (ou outras maiorias) valoram e apresentam a eles. Isso poderia talvez ajudar a pensar sobre a questão da língua em uma perspectiva que não é imediatamente ocupada por considerações políticas, sociológicas ou psicológicas externas, o que de forma alguma significa que elas não sejam importantes. Espera-se que uma abordagem pedagógica da língua escolar elucide como a educação escolar é intrinsecamente (desde uma perspectiva interna) política, ainda que não no sentido de ser instrumental para objetivos políticos prédefinidos fora da escola. 
Mover-se além dessas considerações políticas externas e abordar a questão da língua escolar desde uma perspectiva pedagógica é o real desafio que temos a encarar. Uma vez mais, parece como se fosse impossível discutir a língua da escola sem imediatamente se encontrar, por exemplo, no meio de uma discussão política, ou de ser culpado por sempre portar uma posição política. Nós não queremos ignorar a política envolvida nas questões linguísticas, mas, por introduzir uma perspectiva pedagógica na língua da escola, esperamos que se torne possível olhar para a política da língua escolar desde outro ângulo. A hipótese pedagógica que elaboraremos pode ser formulada como se segue: a língua da escola é sempre uma língua artificial por ter que, por um lado, dirigir-se à próxima geração como uma nova geração e, por outro, tentar transformar 'objetos' (algo do mundo) em matéria de estudo. Educação escolar 'requer' então falar uma língua específica por razões pedagógicas. O efeito é que somente na escola, e enquanto exposta à língua escolar artificial, algo como uma língua materna (a língua falada em casa ou em uma comunidade local) e uma língua paterna (a língua oficial, institucionalizada e/ou estatal), bem como sua relação (conflitiva em potencial), tornam-se um assunto. Provavelmente essas línguas precedam à língua da escola, mas é a escolarização que torna a sua existência e relação um assunto. Por essa razão, nossas reflexões tentarão levar em conta algumas observações e comentários que têm sido feitos relativos à 'língua materna e paterna's. No entanto, tentaremos indicar por que e em que sentido poderíamos dizer que a língua da escola é na verdade a língua 'das crianças (ou talvez melhor, do aluno-pupilo ou estudante) e dos poetas', e por que isso está em realidade implicando uma radical crise ou interrupção da lógica (edípica) de qualquer família (incluindo a 'nacional', a 'nativa' e a 'científica'). ${ }^{6}$

\footnotetext{
5 Essas noções podem ser tomadas de diversas maneiras, nós as tomamos aqui para nos referir à língua (possivelmente línguas no plural) falada em casa, a língua materna, e à língua oficial (possivelmente igualmente no plural), a língua paterna. Esse uso dos termos é diferente, por exemplo, daquele de Thoreau, para quem a língua paterna se refere à língua escrita (literária) (ver STANDISH, 2006), ou de Illich, que não usa a noção de língua paterna, mas faz uma diferença entre a língua vernácula e a materna (ILLICH, 1981/2009). A língua materna seria a língua artificial imposta pelo estado como a oficial.

${ }^{6}$ Com isso queremos dizer que muito frequentemente abordamos a escola do ponto de vista da família (seja no sentido de uma privada, seja no sentido de uma nacional) como um lugar onde a
} 


\section{a lingua de escola: um caso de amor}

Talvez primeiro seja importante esclarecer em mais detalhe o que temos em mente quando nos referimos à língua da escola. Ela pode significar pelo menos duas coisas. Primeiramente, aquilo que muitas vezes se chama a língua de instrução ou comunicação, e então a língua comum na qual ou através da qual estudantes aprendem. Em segundo lugar, há a língua ou, frequentemente, as línguas que estudantes aprendem (a falar, escrever, ...) na escola ou que estudantes aprendem sobre ou estudam durante o tempo escolar. Nosso foco está sobretudo no primeiro sentido, isto é, a língua que é parte de práticas pedagógicas em escolas, e que é falada por professores e (ao menos assumido ser) entendida por estudantes. Como anunciado mais cedo, formularemos a hipótese de que essa língua é sempre artificial, não é uma língua 'natural' (nem vernácula nem nativa), tampouco um tipo de língua 'sagrada' que é conservada ou protegida por uma autoridade política ou qualquer outra. Com uma língua ser artificial queremos dizer que ela é sempre de alguma forma 'feita'. Para dizê-lo realmente sem rodeios: ninguém realmente fala a 'língua de escola' em casa ou no trabalho (exceto professores escolares). Quando deixam a família e entram na escola, os estudantes são muitas vezes confrontados com uma língua que difere daquela que eles estavam usando para falar. A língua falada em casa pode ser uma outra língua completa, ou um tipo de dialeto. Nesse ponto, faremos uma declaração forte: a diferença entre dialetos e línguas não é o maior problema aqui, o que importa é que a língua de escola é sempre diferente daquela falada, por assim dizer, 'antes' da escola. Mas a língua falada na escola é também diferente da língua (ou línguas) faladas 'depois' da escola. Essas podem ser dialetos, mas também as línguas institucionalizadas e protegidas ou oficializadas de uma comunidade ou país. É claro, a língua escolar tem conexões com essas outras línguas, mas é sempre uma língua transformada, modificada.

busca por identidade, o complexo identitário ou a luta entre pai e mãe, é acenada. Todavia, sustentamos que a escola, onde cada um se torna um aluno-pupilo como qualquer outro (e lembramos que um dos sentidos principais do Latim 'pupillus' é 'órfão'), interrompe essa lógica de Édipo dentro de qualquer família. 
Levando em conta as características típicas da escola como forma pedagógica, e considerando a língua de escola como sendo parte da organização escolar pedagógica, há pelo menos duas razões para que a língua escolar seja artificial, ou mais precisamente: duas operações pedagógicas que a língua escolar faz.

A primeira é que a escola é o lugar onde a matéria de estudo deixa uma marca na língua. Tomemos o exemplo do professor de física, história ou matemática. Uma língua específica - no caso extremo uma altamente formalizada ou simbólica - é necessária para que o mundo (de física, história e matemática) torne-se um objeto de estudo. Não é somente que certas palavras não sejam (ainda) parte do vocabulário usado na família ou comunidade local. Nem é apenas que a língua escolar seja mais formal. É provável que tudo isso seja assim. Mas a questão central não é apenas a diferença entre o código restrito e o elaborado, que oculta diferenças de classe, como mencionado por Bernstein. O que queremos frisar é que a língua de escola é sempre parcialmente marcada, ou ainda coconstruída, pela matéria de estudo. E por essa razão é sempre uma língua que de alguma forma é 'esvaziada' ou 'limpada' de todo tipo de imposições ou apropriações (culturais, sociais, políticas, ...), exatamente porque ela é utilizada para apresentar o mundo aos estudantes, ela quer nomear o mundo sem já fechálo7. Não há, é claro, tal coisa como uma língua completamente neutra, mas a língua na escola - pelo menos no momento em que ela contribui a 'fazer' escola - é bem-sucedida em nomear o mundo (e trazer algo para o primeiro plano) sem todos os tipos de imposições e reinvindicações de uma mão superior.

A segunda razão para o caráter artificial da língua de escola é que nas escolas - ao menos no sentido em que nós usamos o termo escola - está se falando

\footnotetext{
${ }^{7}$ Neste contexto, temos que fazer referência explícita a Paulo Freire, que no terceiro capítulo de sua Pedagogia do Oprimido afirma que palavras 'reais' são sempre, ao mesmo tempo, ações (sem ser ativismo), elas são ações sobre o mundo, o que em nosso entendimento implica que, como palavras, elas não são apropriadas. Elas nomeiam o mundo e, por fazerem isso, podem transformálo. E as mesmas palavras (por exemplo, a capital do Pará é Belém) podem ser ditas como palavras reais (isto é, quando essas palavras conseguem significar ou vir à vida, como também quando podem receber nova significação) ou como palavras alienantes (quando elas são apenas conhecimento morto).
} 
à próxima geração, convidando-a a deixar o próprio mundo da vida. Isso é sobre expor e reunir jovens pessoas ao redor de uma matéria (objeto) de interesse. Em outras palavras, é uma língua que deve ter a força de reunir e expor de tal maneira que pessoas jovens tomem lugar na '(ex-)posição' onde elas se tornam estudantes, e então, sejam capazes de começar a dar significado elas mesmas ao mundo e sejam capazes de 'formarem-se' por meio de prática e estudo, por meio de destrezas e conhecimento. Enquanto tal, essa língua está convidando a falar, e então é sempre também uma língua que pode se aproximar, que pode ser esticada, que pode ser mudada sem muitas consequências. Em um certo sentido, é um tipo de língua poética: ela pode dirigir-se a alguém e, enquanto convida e mostra, ela realmente não impõe expectativas. Língua escolar aqui é uma língua que permite à próxima geração de fato tornar-se uma nova geração e, então, uma língua que não é exigida por professores (ou outros), mas sim uma língua de palavras que podem ser $\mathrm{d}(\mathrm{o})$ adas.

Combinando ambos os aspectos, e valendo-se das ideias de Arendt, a língua de escola é um (estranho) tipo de língua amorosa que põe em cena o amor conjunto pelo mundo e o amor pela nova geração. Ela é a língua de nomear (sem fechar), de convidar (sem interpelar), de fazer algo (matéria de estudo) falar (sem silenciar estudantes), de dar palavras (sem impor definições fechadas ou pedir por retorno), de hiper-funcionalidade (exatamente porque remove funções específicas). Provavelmente isso também mostra que a língua escolar é algumas vezes próxima da língua de 'poetas' por um lado (língua para nomear, convidar, inspirar, fazer falar) ${ }^{8}$ e da língua de ciência ou língua acadêmica por outro lado (fortemente

\footnotetext{
${ }^{8}$ Como parênteses, é interessante notar que dos sofistas, aos quais devemos a primeira articulação da crença de que seres humanos têm que encontrar seu próprio destino e, nesse sentido, são relacionados à emergência de 'escola', diz-se terem continuado a tradição dos grandes poetas gregos. Estes não estavam a serviço de Apolo, o deus da sabedoria, mas receberam sua língua de Mnemosyne, a deusa da memória, e de suas filhas, as Musas, que em primeiro lugar contam e recontam 'estórias', comunicam seu entusiasmo e inspiração - e não impõem - 'significando' e, nesse sentido, podem contribuir a 'formar' pessoas ou a permiti-las se autoformarem. Essa formação implica crucialmente memória e apresentação. Isso está dizendo que, para os contadores de histórias orais memorizarem o conteúdo, os poemas abrigavam muita repetição e usavam epítetos formulados para manter a estrutura do hexâmetro. Eles foram, poderíamos dizer, gramaticalizados. E nós poderíamos recordar que a Ilíada e a Odisseia foram transmitidas para nós no dialeto grego épico, o qual é um dialeto puramente literário, combinando vocabulário e até
} 
funcional e língua abstraidora), por ambas serem línguas também fortemente esculpidas ou feitas (e língua nativa de ninguém). Mas essas línguas são ao mesmo tempo muito diferentes da língua escolar. Ela não é apenas sobre alcançar o mundo, mas sempre também a próxima geração. Por isso provavelmente a observação demasiadamente ouvida (como uma queixa) de o professor ser muito 'artificial e afetado' ou muito 'acadêmico' em sua fala. Mas isso também poderia explicar por que ainda assim a língua de escola é também simultaneamente uma língua bastante familiar, isto é, que alcança a vida familiar e o mundo da vida dos estudantes. Mas novamente, não é a língua 'deles', e se a língua escolar se tornasse língua deles, seria difícil alcançar o mundo (para além do mundo da vida deles). Seria difícil fazê-los expostos e dar ao mundo uma chance (de contestar, tocar etc.). Poder-se-ia dizer que a língua dentro da organização escolar - e quando ela realmente trabalha como uma organização escolar - é um (puro) meio de comunicação ou, talvez mais precisamente, um meio de tornar comum.

Deveria estar claro que, em nossa visão, a questão da língua de escola é na verdade relativa à óbvia questão de como gerações podem se comunicar. Todavia, é importante ser mais preciso nesse ponto. O problema de gerações, em nossa visão pedagógica, não se refere a uma questão de idade ou tempo que implique a assunção de que gerações são dadas e evoluem (como um tipo de lei da natureza). Gerações são sempre feitas, e elas vêm a ser o resultado de pôr alguma coisa sobre a mesa e deixá-la livre. Elas não são pré-existentes a esse ato escolar. O ato escolar faz uma nova geração possível, e isso implica que a língua escolar é artificial, e na verdade nunca pode ser dominada, mas sim aberta para uso livre. Se é assim, deveríamos evitar tornar o problema da língua escolar tão rapidamente um problema político de línguas majoritárias e minoritárias ou de línguas oficiais e aquelas que não são oficialmente reconhecidas ou protegidas. A língua na escola e de novo temos que enfatizar: se ela trabalha como uma língua escolar - não pode nunca ser apenas a língua majoritária (nem a minoritária). Claramente, a língua por si só nunca é 'nativa', e sempre crucialmente artificial (ou mesmo ficcional, isto é, 'feita'). 
escolar é sempre a língua da maioria, ou mais próxima da língua dela, mas não é (mais) sua língua.

\section{explorando as consequências de uma hipótese}

Os prévios, curtos esboços deveriam ser suficientes para esperançosamente - formular nossa hipótese: a língua de escola é sempre uma língua artificial (purificada, funcionalizada,...) que permite à nova geração nomear o mundo e, enquanto faz isso, transformar eles mesmos em uma nova geração. Essa hipótese pode também ser formulada de uma maneira mais radical: não importa qual língua é falada na escola, mas quando uma língua se torna uma língua escolar, a escola impõe certas operações sobre a língua, a fim de ser capaz de operar como uma escola. Esperamos que a hipótese tenha alguma credibilidade no sentido de estar preparada para ser melhor pensada ao longo dessas linhas e para explorar suas consequências. Mas ela é uma hipótese real para nós, significando que não estamos (ainda) certos se essas consequências podem sustentar a hipótese ou miná-la completamente.

Uma consequência - e de certo modo ela é consideravelmente radical seria que a língua escolar não é apenas uma língua artificial, mas que ao mesmo tempo é muito arbitrário e parcialmente contingente qual língua é falada na escola. Ela é arbitrária posto que as conexões (e as expectativas relacionadas a essas conexões) com sua língua materna ou paterna são suspensas. Para reformular isso: a língua escolar sempre vem de algum lugar (e de fato, provavelmente muitas vezes por meio de imposição ou outros jogos de poder declarados ou menos declarados), mas sua genealogia (e obrigações de família - para com a mãe/casa ou o pai/nação) deveria ser suspensa a fim de oferecer à próxima geração educação escolar. Língua escolar é de algum modo uma escolha arbitrária, mas uma escolha que impõe responsabilidades pedagógicas específicas que nós exploramos nas próximas consequências. Há um elemento adicional aqui: já que escola é sobre a possibilidade de relacionar-se com aquilo que está definindo a vida de alguém (isto é, sobre emancipação), e não apenas sobre estar imerso ou incluído nela, a escola deveria sempre pelo menos incluir a profanação da língua 
materna (ou da língua da família). O que significaria que, por exemplo, para uma família árabe vivendo em Bruxelas, o Árabe deveria estar presente na escola, mas como matéria de estudo da maneira como indicamos antes.

A segunda consequência é que, posto que a língua de escola é uma língua que não é (ainda) muito falada por estudantes (em variados graus), é responsabilidade da escola - fora do amor pela próxima geração - ensiná-los ou aprender a falar a língua de escola. Para pôr de forma direta: esse é de fato um assunto didático, e dever-se-ia ser cuidadoso para não transformá-lo tão rapidamente em um assunto cultural, social e político. Por ter (ou 'escolher') uma língua escolar específica, diferentes estudantes (de diferentes origens) estão imediatamente em um começo ou posição de início diferente, e a escola tem que compensar ou remediar isso. De novo, sugerimos olhar para isso não imediatamente em termos de atos de imposição cultural ou de uma matéria de raciocínio deficitário e 'tratamento' imposto. Esse enquadramento (crítico) somente faz sentido se a língua escolar é abordada em termos de minoria ou maioria, família ou língua oficial. Como esclarecido mais cedo, preferimos concebê-la como uma coisa intergerações e artificial, então a questão é provavelmente em primeiro lugar 'didática' (isto é, como compensar a diferença na situação de início?).

A terceira consequência é que, provavelmente, na educação escolar a língua paterna ou materna é ao mesmo tempo transformada em uma matéria de estudo. E nesse sentido ela também se torna uma língua que começa a gaguejar, hesitar, desfazer-se, tornar-se analisada, estar invertida, recomposta, recriada - a língua de um estudante/criança. De novo, temos que ser mais precisos nesse ponto. A existência da língua escolar artificial, e desde que sendo confrontado com ela, faz algo aparecer como uma língua materna ou paterna (similar à ideia de que a existência da escola transforma a sociedade em uma matéria de interesse). Talvez esta seja a primeira responsabilidade para com a próxima geração: gramaticalizar a língua paterna ou materna, e permitir que a língua se torne um objeto de estudo, 
que seja algo para se relacionar com (em vez de estar completamente absorvido ou imerso nela).

Isso implica, primeiro, que a língua deveria ser 'disponibilizada' ou 'dada' de algum modo, ela tem que ser a(re)presentada ou deveria ser possível tê-la a mão, por assim dizer (dedicar-se a ela e tratar dela de novo e repeti-la). Portanto, a língua tem que primeiro ser gramaticalizada, no sentido de que ela deveria ser 'escrita' (em um sentido amplo). Isso significa que não podemos ter escola sem escrever. Escrever faz isto possível, que nós possamos retornar ao que é dito, ao que é conhecido, possamos arquivá-lo, transmiti-lo, analisá-lo como um 'objeto', começar com ele de novo etc. Segundo, a gramaticalização se refere também à gramática não apenas no sentido estrito, mas mais amplamente à externalização e materialização daquilo que usualmente permanece vedado (os elementos, regras, definições, princípios básicos...). 'Naturalmente' você não encontrará a língua transformada em letras para ser encontradas no alfabeto e na caixa de letras. Sem essa gramaticalização do 'natural', privamos as crianças de se relacionarem com o mundo e com aquilo que as define em larga medida (isto é, precisamente a língua). Então há de fato uma diferença entre 'aprender fazendo' e 'aprendizagem escolar'. Mesmo que de fato as gramáticas muitas vezes sejam chatas e, em termos de uso imediato, frequentemente muito inúteis, é o conhecimento das gramáticas (no sentido amplo) que nos permite não ser apenas absorvidos na e pela língua, mas sim ser envolvidos e à distância escapar de ser aprisionados ou trancados no nosso mundo da vida ${ }^{9}$. Podemos reformular isso como segue: se uma escola afirma que Português ou Holandês é a língua escolar, ela deveria reconhecer que não apenas ela é Português escolar ou Holandês escolar (como uma língua

\footnotetext{
$9 \mathrm{E}$ também aqui pensamos que estamos muito próximos à prática educacional efetiva que Freire definiu. De fato, ela era sobre alfabetização em termos de escrita e leitura como uma gramaticalização do mundo da vida. Especialmente se alguém olha às velhas imagens dessa prática, pensamos que aquilo que esse alguém pode ver é como o 'natural' mundo da vida se torna 'escrito', a fim de ser capaz de relacionar-se com ele ao invés de ser aprisionado nele. Aqui podemos encontrar a emancipação ou força política da escola mesma no sentido que explicamos acima. Uma força política que não é derivada do fato de que poderia ser instrumental a um projeto político particular concebido ou planejado por outros, mas que é internamente relacionada à prática que permite uma distância por meio de operações escolares efetivas (incluindo a gramaticalização e baseadas no amor de que temos falado a respeito).
} 
materna ou paterna), mas simultaneamente permitir aos estudantes relacioná-la à sua língua materna ou paterna.

A quarta consequência é que a escola tem que oferecer sempre mais de uma língua para ser aprendida e estudada como matéria de estudo. Isso é na verdade uma forte maneira (a única?) de contribuir à profanação da comunicação, isto é, de permitir aos jovens experienciarem a habilidade/potencialidade de se comunicar e a habilidade/potencialidade de traduzir. Mais línguas ajudam a evitar que se transforme a língua escolar em uma ferramenta para batizar a nova geração. Aqui temos que manter em mente que essas línguas também se tornam um objeto de 'estudo' (não apenas de prática). Ou posto diferentemente: na escola pelo menos duas línguas deveriam ser gramaticalizadas a fim de permitir a crucial experiência de 'traduzibilidade'. A experiência de estar-em-meio-a ou, como Michel Serres afirma, na dobra do dicionário. No Trovador do conhecimento, Serres (1997) expressa sua profunda gratidão por ter sido forçado, sendo canhoto, a aprender na escola a escrever com a mão direita. Ele se tornou um 'canhoto impedido', ou melhor, uma 'metade concluída' ('corpo concluído') que fez a experiência de 'maneabilidade' tal qual e a chamou, contrariamente ao que 'nós' hoje esperaríamos, o mais revolucionário evento de sua vida. Disso podemos guardar que a escola tem a ver com uma força que nos desvia de nossa 'direção natural', força-nos a cruzar o rio e deixar nosso ninho. Isso pôs em marcha uma mutação (incluindo um sofrimento, mas também uma alegria) sem a qual, de acordo com Serres, nenhuma aprendizagem real tem lugar. Relatando essa mutação, essa "travessia das crianças" (a qual é "o significado desnudo da palavra grega pedagogia"), ele usa a imagem de alguém que nada atravessando um largo rio, deixando uma margem na qual ele permanece (ou à qual pertence), por exemplo uma língua - diga-se Português -, para chegar à outra margem onde ele permanece de novo (ou à qual pertence) - diga-se Inglês. No entanto, Serres nos incita a não esquecer o nado e o rio no meio ou o meio como rio; “[...] no meio da travessia, até o chão está faltando; qualquer sentido de pertencimento, de suporte se foi" (SERRES, 1997, p.5). Cruzando o rio alguém chega à outra margem onde a outra língua é falada, 
mas ele passa no meio de um 'terceiro mundo', "desde o qual não se tem direção, para encontrar todas as direções" (SERRES, 1997, p.7). Passar um umbral sem (uma) referência (ou onde todas as referências são abandonadas ou estão igualmente distantes), estar muito sensível: "tempo e lugar de extrema atenção", “sendo nada mas potencial" (SERRES, 1997, p.25). Essa pessoa, agora, não simplesmente fala duas línguas, mas passa "incessantemente por meio da dobra do dicionário", "habitando ambas as margens e perseguindo o meio [...] desde o qual divergem vinte ou cem mil direções" (SERRES, 1997, p.6). Então aprender outra língua, passando a dobra do dicionário, como uma travessia pedagógica, permite essa experiência de traduzibilidade - a qual também talvez sempre envolva a experiência do que é 'ter' uma língua.

A quinta e final consequência que queremos realçar muito brevemente é que domesticar a língua de escola (por meio da imposição de línguas oficiais ou de outras majoritárias) é provavelmente a primeira e provavelmente também uma maneira muito efetiva de domar e neutralizar a escola10. Fazer da língua escolar uma língua oficial (a língua do estado ou de qualquer outra autoridade) sempre implica transformar a educação escolar em um modo de socialização (e assim de reprodução). E isso também explica que contrarreações a essa domesticação através de políticas linguísticas não são provavelmente de fato efetivas se elas (somente) impõem uma língua minoritária como nova língua escolar. O resultado de uma tal política de minoria é frequentemente que a escola é transformada em um lugar de contrassocialização e usada para a produção de uma nova sociedade

\footnotetext{
${ }^{10}$ Pensamos que isso é o que Illich 'esquece' em sua análise (Illich, 1981/2001) da maneira pela qual a imposição de uma 'língua materna' (isto é, "a língua que as autoridades do estado têm decidido que deve ser a primeira língua de cada um") é na verdade uma forma de minar ou capitalizar o comum (o vernáculo) e fazer pessoas confiarem em uma instituição que as ensina essa 'língua materna'. Para Illich, a escola é a instituição do estado que, em primeiro lugar, ensina as pessoas que elas precisam dessa instituição (e assim se tornam dependentes) para se tornarem livres ou independentes (para serem capazes de participar na comunicação). Nós pensamos, no entanto, que ele está confundindo totalmente 'escola' como uma forma pedagógica em nosso sentido com a instituição do estado. Ele está de fato tomando uma perspectiva funcionalista externa e negligenciando os elementos que ele mesmo parece reconhecer (nesse texto e em outros, por exemplo aqueles sobre alfabetização e visualização, que também implicam uma gramática, artifício, uma distância do oral por meio da escrita e uma distância da escrita por meio da leitura em voz alta) como sendo importantes por possibilitar o estudo e que, segundo nós, podem ser relacionadas à 'escola' como a entendemos. Ali parece estar uma constante flutuação do vernáculo para o oral e implicitamente também (a)o 'natural' ou 'nativo'.
} 
que a velha geração tem em mente para a próxima geração. O risco aqui é que a próxima geração seja privada de escolarização (é apenas socializada) e então da possibilidade de se tornar uma nova geração. Talvez a escola seja o lugar errado para desenrolar políticas de linguagem e conexas guerras políticas e culturais de identidade. Isso não quer dizer que essas guerras não sejam importantes, mas que deveríamos ser cuidadosos para que elas sejam travadas em um tempo e lugar organizados fora do amor por ambos, o mundo e a geração vindoura.

Pedimos para não entender isto como uma defesa da escola como um local seguro de paz e entendimento. Isto é nossa expressão da forte confiança em que a sociedade pode ser mudada e renovada, em que a emancipação é possível por meio da escola, também em que uma 'luta' intergerações é diferente (e talvez mais profícua a longo prazo) de uma guerra política ou cultural em termos de identidade (isto é, em termos da luta de Édipo entre uma língua materna e uma língua paterna). Mas somente se dermos também à escola e sua língua uma chance. A simples e ao mesmo tempo radical resposta à questão 'que língua falar na escola?' (por exemplo em Bruxelas ou qualquer outro lugar) é: isso não importa, contanto que sua gramaticalização e estudo sejam admitidos junto com a gramaticalização de outra língua. E provavelmente esses atos escolares envolvem uma política muito mais radical que a política identitária corrente sobre cultura e linguagem.

\section{referências}

BERNSTEIN, B. Class, Codes and Control. London: Routledge, 1971.

BOURDEIU, P.; PASSERON, J. La Reproduction. Éléments pour une théorie du système d'enseignement. Paris: Éditions de Minuit, 1970.

FREIRE, P. Pedagogy of the oppressed. New York: Herder and Herder, 1968/1970.

ILICH, I. Shadow Work. London/New York: Marion Boyars, 1981/2009.

MASSCHELEIN, J.; SIMON, M. Em defesa da escola. Uma questão pública. Coleção Educação: Experiência e sentido, Belo Horizonte: Autêntica, 2014.

SERRES, M. The Troubadour of Knowledge. Ann Arbor: University of Michigan Press, 1997. STANDISH, P. Uncammon Schools: Stanley Cavell and the Teaching of Walden. Studies in Philosophy and Education, 25, p.145-157, 2006.

received in: 11.03.2017 